\title{
Dorothy Kaufmann, Edith Thomas, passionnément résistante
}

Paris, Éditions Autrement, 2007, 267 pages, préface de Michelle Perrot (traduction de Edith Thomas, A Passion for Resistance, Cornell University Press, 2004).

\section{Françoise Thébaud}

\section{(2) OpenEdition}

12 Journals

Édition électronique

URL : https://journals.openedition.org/clio/9142

DOI : $10.4000 /$ clio.9142

ISSN : 1777-5299

Éditeur

Belin

Édition imprimée

Date de publication : 15 décembre 2008

Pagination : 275-307

ISSN : 1252-7017

Référence électronique

Françoise Thébaud, "Dorothy Kaufmann, Edith Thomas, passionnément résistante », Clio. Histoire,

femmes et sociétés [En ligne], 28 | 2008, mis en ligne le 16 décembre 2008, consulté le 24 avril 2022.

URL : http://journals.openedition.org/clio/9142 ; DOI : https://doi.org/10.4000/clio.9142

Ce document a été généré automatiquement le 24 avril 2022.

Tous droits réservés 


\title{
Dorothy Kaufmann, Edith Thomas, passionnément résistante
}

\author{
Paris, Éditions Autrement, 2007, 267 pages, préface de Michelle Perrot \\ (traduction de Edith Thomas, A Passion for Resistance, Cornell \\ University Press, 2004).
}

\section{Françoise Thébaud}

1 Spécialiste de littérature française $\mathrm{du} \mathrm{xx}^{\mathrm{e}}$ siècle, Dorothy Kaufmann avait déjà sorti de l'ombre Edith Thomas en 1995, en publiant et annotant, à l'occasion du $50^{\mathrm{e}}$ anniversaire de la fin de la Seconde Guerre mondiale, des écrits inédits concernant cette période : extraits d'un journal intime tenu entre 1931 et 1949, satire écrite entre octobre 1940 et mai 1941 sous la forme du journal fictif d'un bourgeois pétainiste, Mémoires rédigés en 1952 et intitulés Le Témoin compromis ${ }^{1}$. La chercheuse soulignait alors l'intérêt de faire dialoguer des ego-textes de nature différente : un journal discontinu où Edith Thomas notait ses observations immédiates et ses critiques sur le régime de Vichy et les années noires; une autobiographie soucieuse de cohérence et de justification après sa démission douloureuse du Parti communiste en 1949 (à l'heure de la dénonciation du titisme et du procès Rajk) et sa rupture avec Jean Paulhan à propos de la Résistance. Elle révélait aussi le rôle d'Edith Thomas dans la Résistance, figure majeure du Comité national des écrivains, collaboratrice des Lettres françaises et des Éditions de Minuit. Elle suggérait enfin l'importance de cette expérience collective dans l'itinéraire d'une femme dont les écrits d'avant-guerre développaient le thème de la solitude.

2 Fruit de plus de dix années de recherche, la biographie aujourd'hui publiée élargit le propos. Elle offre le portrait empathique d'une intellectuelle engagée contre l'oppression politique, sociale et sexuelle, mais aussi celui d'une femme passionnée aux multiples secrets, pour reprendre le terme de la belle préface de Michelle Perrot. De facture classique (quinze chapitres chronologiques), elle affirme en effet la volonté et la possibilité de rendre compte non seulement de la vie professionnelle et politique d'Edith Thomas, mais aussi de sa vie personnelle et intime grâce à une "manne autobiographique tombée du ciel»(p.31). Cette manne comprend les inédits (notamment le journal, les Mémoires et une lettre imaginaire adressée au frère après sa 
mort) confiés à la chercheuse par Dominique Aury ${ }^{2}$ - auteure longtemps anonyme d'Histoire d'o, amie de longue date et amante d'une année-, ainsi que les correspondances entre Edith et Dominique d'une part, Edith et Jean Paulhan d'autre part. Ces documents complètent l'abondant dossier Edith Thomas des Archives nationales (écrits laissés par elle-même), les textes publiés et les témoignages recueillis auprès de collègues et ami(e)s.

Qui est donc Edith Thomas (1909-1970), morte prématurément à 61 ans d'une hépatite fulgurante, et pourquoi est-elle si peu connue aujourd'hui ? Contemporaine de Simone de Beauvoir (1908-1986), dont la renommée personnelle et celle du couple formé avec Jean-Paul Sartre l'ont sans doute reléguée dans l'ombre ${ }^{3}$, Edith Thomas est chartiste de formation et archiviste-paléographe, une profession relativement ouverte aux femmes diplômées dès les années 1920. Écrivaine qui a expérimenté la plupart des formes d'écriture, elle est l'auteure de poésies, de pièces de théâtre, de sept romans, de deux recueils de nouvelles, de huit études historiques et biographiques (toutes publiées après la guerre), et de centaines d'articles de journaux écrits entre les années 1930 et les années 1960. D'un combat à l'autre, elle s'est en effet engagée, outre la Résistance, contre la misère sociale, pour les Républicains espagnols (effectuant deux voyages en Espagne en 1936 et 1938), pour la liberté d'expression et le débat d'idées, contre la torture en Algérie et la censure d'État (membre à cet effet du groupe qui édita VéritéLiberté), contre la place restreinte faite aux femmes. En janvier 1945, elle démissionne de la rédaction de Femmes françaises, faute de marge éditoriale suffisante et parce que la revue a des accents trop familialistes. Féministe sans utiliser un terme très décrié à l'époque, elle écrit L'humanisme féminin (anthologie historique de textes écrits par des femmes de lettres françaises qui ne fut jamais publiée par la maison d'édition communiste pressentie en 1949) et considère qu'il faudrait «donner à chaque être humain, homme ou femme, la possibilité de développer entièrement et harmonieusement sa personne ». De même, ses biographies, à l'exception de Rossel paru en 1967, mettent en scène des femmes avec lesquelles elle partage " une connivence secrète ", un engagement de conscience dans les luttes politiques et sociales de leur temps : notamment Pauline Roland (1805-1852), féministe et socialiste, George Sand, Louise Michel et plus généralement les femmes de 1848 ou les communardes.

Pour Dorothy Kaufmann à la recherche d'une compréhension profonde de son personnage, Edith Thomas, qui critiqua à plusieurs reprises les œuvres de Sartre et de Simone de Beauvoir, peut être caractérisée par la quête d'une cohérence entre les actes et les convictions, le refus de toute compromission, le rejet de l'absurde et le respect de l'humain. Mais ce "grand seigneur exilé » selon les mots de Dominique Aury est aussi une femme parfois dépressive, otage d'un corps qui la fit beaucoup souffrir (de tuberculose osseuse qui la laissa boiteuse, puis de tuberculose pulmonaire), fidèle à un lien très fusionnel avec son frère, passionnée en quête d'amour et de maternité, mais timide envers la sexualité (sauf peut-être pendant la liaison initiée par son amie). Historicisés, ces éléments d'intimité enrichissent la biographie proposée, qui, traversée des deux premiers tiers du vingtième siècle, est une contribution importante à l'histoire des femmes intellectuelles, si souvent oubliées jusque dans l'historiographie et la mémoire contemporaines ${ }^{4}$. Elle est aussi une invitation à lire ou relire les écrits d'Edith Thomas, dont ses travaux pionniers en histoire des femmes, et pourrait permettre la publication actuelle de L'humanisme féminin. 


\section{NOTES}

1. Edith Thomas, Pages de journal, 1939-1944 suivies de Journal intime de Monsieur Célestin Costedet, présenté par Dorothy Kaufmann, Paris, Editions Viviane Hamy, 1995 ; Edith Thomas, Le Témoin compromis, présenté par Dorothy Kaufmann, Paris, Editions Viviane Hamy, 1995.

2. Sur Dominique Aury, voir Angie David, Dominique Aury, Paris, Editions Léo Scheer, 2006.

3. Son départ précoce du Parti communiste, rejoint à l'automne 1942, y a aussi contribué.

4. Voir Florence Rochefort (dir.), «Intellectuelles ", Clio, Histoire, Femmes et sociétés, 13, 2001 et Nicole Racine, Michel Trebitsch (dir.), Intellectuelles. Du genre en histoire des intellectuels, Bruxelles, Complexe, 2004. Séverine Liatard publiera prochainement un livre issu de sa thèse de doctorat sur Colette Audry (1906-1990), autre intellectuelle contemporaine d'Edith Thomas ou de Simone de Beauvoir. 